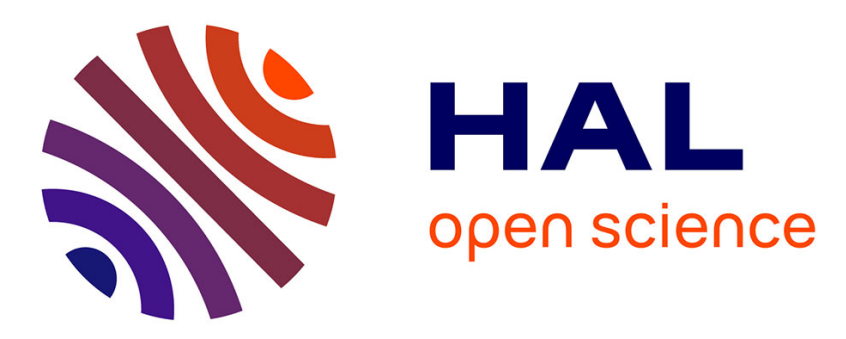

\title{
Fabrication of Activated Carbon Electrodes by Inkjet Deposition
}

\author{
Véronique Conédéra, Fabien Mesnilgrente, Magali Brunet, Norbert Fabre
}

\section{To cite this version:}

Véronique Conédéra, Fabien Mesnilgrente, Magali Brunet, Norbert Fabre. Fabrication of Activated Carbon Electrodes by Inkjet Deposition. The Fourth International Conference on Systems (ICONS 2009), Feb 2009, Cancun, Mexico. 5p. hal-01867615

\section{HAL Id: hal-01867615 https://hal.science/hal-01867615}

Submitted on 4 Sep 2018

HAL is a multi-disciplinary open access archive for the deposit and dissemination of scientific research documents, whether they are published or not. The documents may come from teaching and research institutions in France or abroad, or from public or private research centers.
L'archive ouverte pluridisciplinaire HAL, est destinée au dépôt et à la diffusion de documents scientifiques de niveau recherche, publiés ou non, émanant des établissements d'enseignement et de recherche français ou étrangers, des laboratoires publics ou privés. 


\title{
Fabrication of Activated Carbon Electrodes by Inkjet Deposition
}

\author{
Véronique Conédéra, Fabien Mesnilgrente, Magali Brunet, Norbert Fabre \\ LAAS-CNRS, Université de Toulouse, 7 Av. du Colonel Roche 31077 Toulouse, France \\ conedera@laas.fr,fabien.mesnilgrente@laas.fr,mbrunet@laas.fr,nfabre@laas.fr
}

\begin{abstract}
The inkjet deposition technology turns out to be interesting in various applications when one attempts to reduce manufacturing costs, simplify technological steps, and implement materials that could not be deposited in any other way. One of the limitations however, is the issue raised by resolution which is directly linked to the ejection head manufacturing technology. In this paper, a method of activated carbon deposition based on inkjet is presented. Activated carbon is extensively used in chemistry for its impurity absorption capabilities and in other applications like the fabrication of supercapacitors. It is shown in particular that by using a localized surface treatment with OTS and an activated carbon suspension stabilized by a surfactant, one can get 10 $\mu m$ structures, which are, therefore, much smaller than the ejection head nozzle diameter. To implement and optimize the process, the contact angle measurement technique is utilized.
\end{abstract}

\section{Introduction}

With its high porosity, activated carbon is used as the electrode material for supercapacitors [1]. Standard assembly of supercapacitors is based on stacking up solid active material layers (activated carbon) with a separator between two collectors ("coin cell" package). The resulting coin cell device features a diameter of a few centimetres. The fabrication of miniaturised supercapacitors integrated on silicon substrate is of great interest in diverse microsystems applications that require energy storage. The integrated supercapacitor design that is proposed is then composed of interdigited fingers (collectors) on which the active material has to be deposited. However, the deposition of activated carbon on the gold electrodes is a real challenge. In this work, the deposition of activated carbon was investigated through use of the inkjet technique developed for polymers, oxides, metals and nanoparticles $[2,3,4,5,6]$. So far, no study of the deposition of activated carbon based on inkjet has been reported for grain sizes between $1 \mu \mathrm{m}$ and $10 \mu \mathrm{m}$. To be able to use this method, a suspension that remains stable over time is required. This suspension will consist of an ink obtained by mixing activated carbon (AC) in ethylene glycol solution (carrying fluid), polytetrafluoroethylene (PTFE) which provides a mechanical link between the carbon particles in the substrate [3] and a surfactant, Triton X100 ( p-(1,3,3,tetramethylbutyl) phenoxy-poly(ethylene glycol)) which contributes to the wettability and stability of the emulsion. The aim is first to obtain a stable AC suspension as a function of the surfactant concentration, and then to project this ink onto a gold electrode which is more hydrophilic than the surrounding hydrophobic silica surface. Hydrophobic silica was obtained by means of an octadecyltrichlorosilane (OTS) treatment aiming to concentrate the ink onto hydrophilic zones with a high surface energy that is, onto the gold electrodes. Through evaporation of ethylene glycol, one gets an activated carbon deposition located exclusively on the metal electrode.

\section{Materials and means}

To form the ink, a ethylene glycol solution from Sigma Aldrich was used to mix an alcoholic PTFE nanoparticle suspension from DuPont, with a Triton X100 surfactant from Sigma Aldrich and activated carbon from Kuraray Chemical Co. The OTS was provided by Sigma Aldrich. To measure the contact angle, a Digidrop machine was used while ink deposition was achieved with an Altadrop machine from Altatech Semiconductor. This is an automatic machine cassette to cassette equipped with a single nozzle head. Substrate temperature can reach $150^{\circ} \mathrm{C}$. The temperature of the ejection heads can be adjusted 
up to $120^{\circ} \mathrm{C}$. Thanks to a special tromboscopic system on the machine, the droplet formation and production rate could be controlled. Also, a movie camera was used to display the deposition and to align the drop on the pattern.

\section{Ink and surface preparation}

\subsection{Ink preparation}

Suspensions were prepared by mixing first in ethylene glycol the Triton X100 with PTFE. The activated carbon was added afterwards [7]. The percentage of PTFE was $5 \mathrm{wt} \%$ of the activated carbon Weigth. This suspension was agitated for $12 \mathrm{hrs}$ and placed in a test tube. The suspension behaviour was observed over time. Solutions featuring Triton compositions from $0.0001 \%$ to $5 \%$ were used. The AC composition was set to $3 \%$ weight relative to ethylene glycol. Higher concentrations yielded inks that were extremely difficult to jet.

\subsection{Surface preparation}

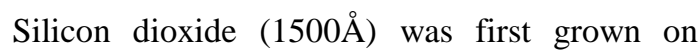
silicon wafer by thermal oxidation followed by the evaporation of $150 \AA$ of chromium and $3000 \AA$ of gold. The electrodes patterns on which activated carbon had to be fixed were formed by photolithography and etching of the chromium/gold layer. Pattern widths varied from $50 \mu \mathrm{m}$ to $10 \mu \mathrm{m}$. On the silicon wafer, zones were defined to make contact angle measurements on the metal or on the oxide.

The silicon dioxide or glass hydrophobic treatment has been extensively reported in the literature [8]. Following cleaning in a sulfochromic solution (2min), samples were soaked into an activation solution with $50 \%$ methanol and hydrochloric acid. After drying under nitrogen, samples were dipped for $30 \mathrm{~min}$ into an OTS solution diluted $2 \%$ in trichloroethylene. To get rid of the remaining solvent and OTS, acetone and deionised water were used.

\section{Results and discussion}

Ethylene glycol is a fluid that can easily be projected by inkjet. Its viscosity is $19.86 \mathrm{mP}$.s at $20^{\circ} \mathrm{C}$ and can equally be reduced by rising temperature. With a boiling temperature at $200^{\circ} \mathrm{C}$, depositions can be achieved at ambient temperature and the behaviour of the droplets deposited on the surface can be observed.
At $140^{\circ} \mathrm{C}$, rapid evaporation was achieved and $\mathrm{AC}$ deposition was almost instantaneous.

\subsection{Variation of the contact angle and of the ink stability as a function of Triton X100 concentration}

The curves in figure 1 show that the contact angle of a suspension on $\mathrm{SiO}_{2}$ or on $\mathrm{Au}$ starts to decrease with a $0.5 \%$ Triton concentration and stabilizes from $2 \%$ onwards. With respect to sedimentation, three situations may

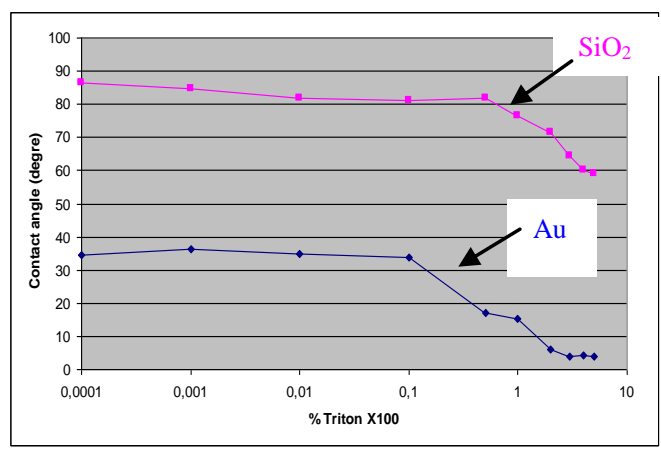

Figure 1 Contact angle variation on $A u$ and $\mathrm{SiO}_{2}$ versus \% Triton $\mathrm{X100}$ weight.

develop according to the Triton concentration after storage $48 \mathrm{hrs}$.

- $\quad$ from $0.0001 \%$ to $0.01 \%$ Triton, three phases can be observed: an upper phase (transparent); a lower phase (opaque) and a carbon precipitation at the bottom of the test tube;

- from 0.01 to $1 \%$ Triton, two phases can be seen: an upper phase (opaque) with numerous particles in suspension and deposition at the bottom of the test tube;

- above $1 \%$, there is only one phase in suspension.

It follows from these findings that only with a percentage in excess of $1 \%$ can a suspension be used. At lower concentrations, the precipitation of the ink storage tank can only cause clogging of the ejection head. The curve of figure 2 shows that the difference in contact angles for gold and silica is highest between 1 and 3\% Triton, thereby facilitating a selective deposition of the ink droplet on the gold electrode. The surface energy 


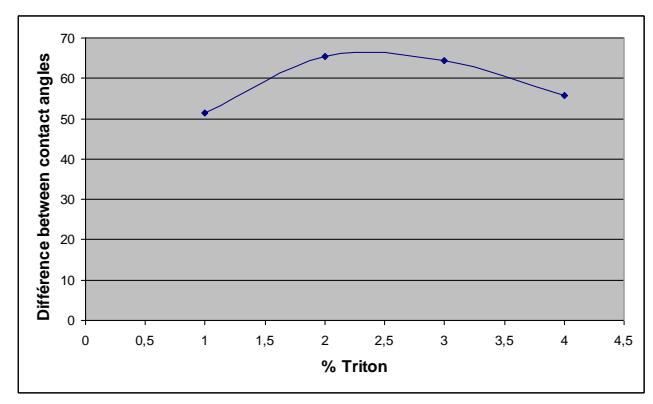

Figure 2 Difference in contact angles for gold and silicon dioxide versus Triton X100\% concentration.

between gold and the ink tends to attract the ink droplet. If the contact angles on $\mathrm{Au}$ and on $\mathrm{SiO}_{2}$ are too small and/or if the difference of contact angles between these two surfaces is too small, the ink droplet will remain in its original position after impact with the surface. As seen in figure 3 with $30^{\circ}$ angles on $\mathrm{Au}$ and $\mathrm{SiO}_{2}$, a denser activated carbon particle distribution appears on the electrode edges. This phenomenon is also referred to as 'the cup of coffee effect' [9].

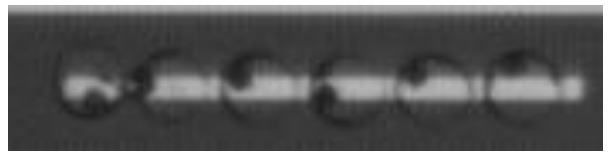

Figure 3 Image with $30^{\circ}$ contact angles on $\mathrm{Au}$ and $\mathrm{SiO}_{2}$.

If the ink droplet is projected outside the pattern onto a surface with a high contact angle, one gets, after ethylene glycol evaporation, a mount as shown in figure 4 .

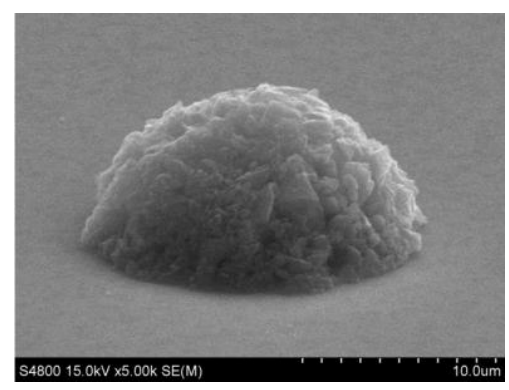

Figure 4 CA deposition onto a high contact angle surface of $\mathrm{SiO}_{2}$.

\subsection{Importance of substrate temperature}

Given the high boiling point of ethylene glycol, one can observe the deposition behaviour at room temperature and then have the ethylene glycol evaporated by a hot plate bake. The results can then be compared to a deposition where the substrate is heated at $140^{\circ} \mathrm{C}$ so as to cause an almost instantaneous evaporation of the droplets during impact on the surface. These operations were achieved with a ink containing 3\% of activated carbon, $3 \%$ Triton, and 5\% PTFE.

\subsubsection{Deposition at room temperature}

Figure 5 shows six ink droplets deposited at room temperature on a $50 \mu \mathrm{m}$ diameter nozzle on a $40 \mu \mathrm{m}$ wide and $650 \mu \mathrm{m}$ long electrode. Clusters of droplets bigger than the $40 \mu \mathrm{m}$ gold line can be observed. This could be a drawback for the case of interdigited electrodes (risks of short-circuits). As ethylene glycol evaporation takes place, one can see that the droplets were joining up figure 5 (b) leading to a relatively inhomogeneous AC particle distribution.

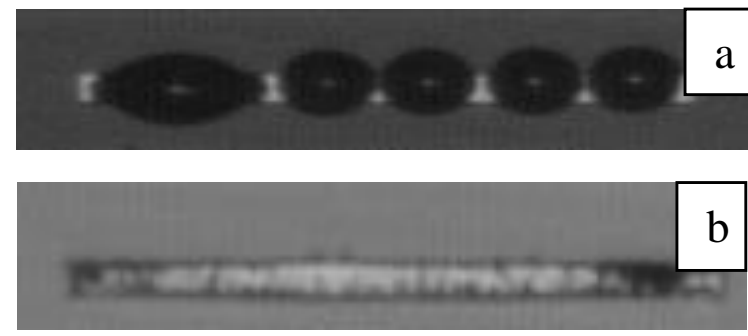

Figure 5 a) Droplets after inkjet printing at room temperature; b) AC dispersion after hot plate bake.

\subsubsection{Deposition at $140^{\circ} \mathrm{C}$}

A homogeneous deposition on the gold electrodes was obtained at $140^{\circ} \mathrm{C}$ by varying the density of the droplets.

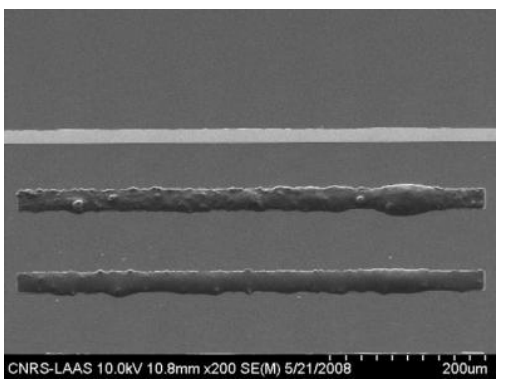

Figure 6 SEM of $30 \mu m$ wide electrodes. 
This was achieved by increasing the number of passes or increasing the number of droplets. Patterns similar to those of figure 6 were obtained on a $30 \mu \mathrm{m}$ wide electrode. This approach was selected for $10 \mu \mathrm{m}$ wide electrodes as shown in figure 7 . The main particles originate from the heterogeneous $\mathrm{AC}$ distribution with grain size of $10 \mu \mathrm{m}$.

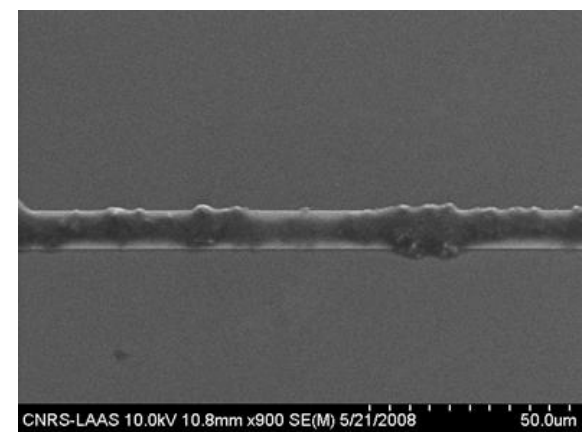

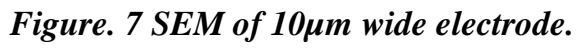

Figure 8 depicts an interdigited electrodes structure
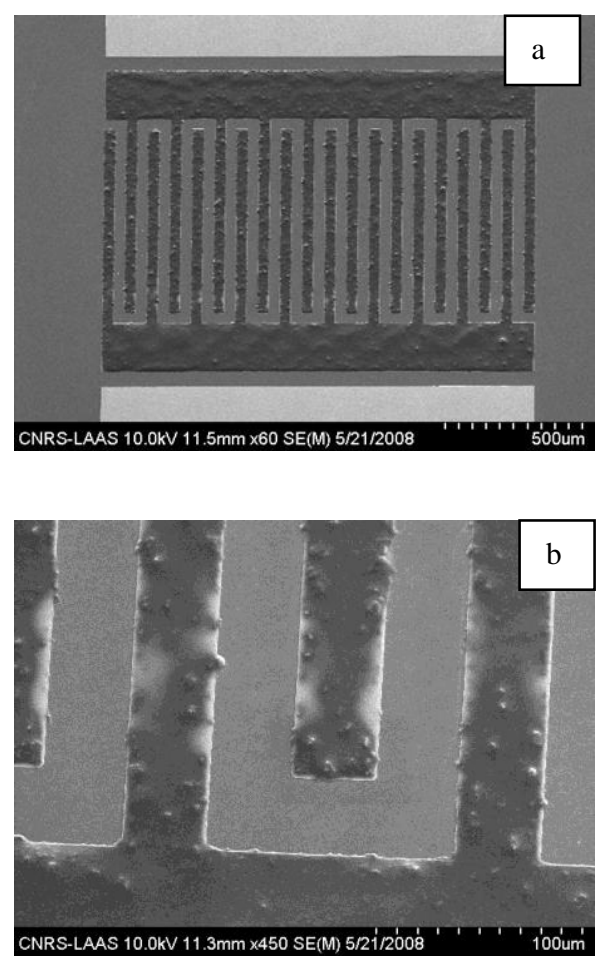

Figure. 8 SEM of an interdigited structure. a) general view; b) detail of the structure.

with a spacing of $40 \mu \mathrm{m}$ between each finger. These structures are then wire bonded for electrical characterisation as supercapacitors [10]. It is also a way for checking that the interdigited electrodes are not short-circuited by the activated carbon.

\section{Conclusion}

The ink jet deposition technology features unique capabilities in terms of materials deposition that cannot be achieved in any other way; the activated carbon example given in this paper demonstrates that good results can only be obtained if the ink jet deposition and the substrate surface condition are fully controlled. This method allows depositions smaller than the nozzle diameter to be achieved, resulting in a higher resolution for a technology which is limited by the inkjet head fabrication constraints or which requires parameter control conditions for the jets [11] which are difficult to master and impossible to implement on certain machines. The developed process consisting in surface functionalizing and suspension improvement through surfactant can be extended to other types of materials in suspension such as nanoparticles. This technique could be adapted for batch processing use of multihead could assure a high throughput.

\section{Acknowledgement}

The authors would like to thank Patrice Simon and Pierre-Louis Taberna from CIRIMAT laboratory in Toulouse, for providing the activated carbon and PTFE solutions and for valuable advices.

\section{References}

[1] A.G. Pandolfo, A.F. Hollenkamp, 'Carbon properties and their role in supercapacitors" journal of Power sources 157 (2006) 11-27.

[2] Whel W.R. ,''Ink-jet printing: the present state of the art' Compeuro '89-3 ${ }^{\text {rd }}$ Annual European Computer Conf., Hambourg, West Ger., 8-12 May 1989; 2/46-52.

[3] R.Adams and R. Lin, ' Ink jet Printing Technologies", Tutorial \# 1, IS\& T's Eight International Conference on Advances in Non-Impact Technologies" Williamsburg, VA, October 25-30, 1992.

[4] Aoife Morrin, Orawan Ngamna, Eimer O’ Malley, Nigel Kent, Simon E. Moulton, Gordon G. Wallace, Malcolm R. Smyth, Anthony J. Killard, " The fabrication and characterization of ink-jet printed polyaniline nanoparticle films"' Electrochimica Acta 53 (2008) 5092-5099.

[5] T. Kayadanova, A. Miedaner, J.D. Perkins, C. Curtis, J.L. Alleman, D.S. Ginley, " Direct-write inkjet printing of 
barium strontium titanate-based tunable circuits" Thin Solid Films 515 (2007) 3820-3824.

[6] Li Yang, Amin Rida, Rushi Vyas, Manos M. Tentzeris, ' 'RFID Tag and RF Structures on a Paper Substrate Using Inkjet-Printing Technology" IEEE transactions on microwave theory and techniques" vol. 5, No. 12 (Dec.2007).

[7] L. Bonnefoi, P. Simon, J.F. Fauvarque, C. Sarrazin, J.F. Sarrau, A. Dugast, "Electrode compositions for carbon power supercapacitors' Journal of Power sources 80 (1999) 149-155.

[8] J.J. Cras, C.A. Rowe-Taitt, D.A. Nivens, F.S. Ligler, " Comparison of chemical cleaning methods of glass in preparation for silanization', Biosensors and bioelectronics 14 (1999) 683-688.

[9] Antje M.J. van den Berg, Antonius W.M. de Laat, Patrick J. Smith, Jolke Perelaer and Ulrich S. Schumbert, 'Geometric control of inkjet printed features using a gelating polymer' J. Mater. Chem., 2007, 17, 677-683.

[10] Magali Brunet, Pierre-Louis Taberna, Patrice Simon, Norbert Fabre, Véronoque Conédéra, Fabien Mesnilgrente, Hugo Durou, Carole Rossi, 'Ink-jet printed carbon-based micro-supercapacitor for mobile self-powered modules' $T o$ be published in proceeding of MRS Fall Meeting, Boston 16 Dec. 2008.

[11] Christian Rensch," Creation of Small Microdrops" Technical Note, Microfab Technologies, Inc. Octobre 2006. 